УДК 625.141

\title{
ВЛИЯНИЕ УСЛОВИЙ ЭКСПЛУАТАЦИИ НА КОЭФФИЦИЕНТ ВНУТРЕННЕГО ТРЕНИЯ В ЩЕБЕНОЧНОМ ОСНОВАНИИ
}

\author{
Шаповалов Владимир Владимирович \\ д.т.н., профессор \\ Коваленко Олег Игоревич \\ Черный Владислав Игоревич \\ Нубарян Даниил Владимирович \\ Шведов Александр Юрьевич \\ ФГБОУ ВО «Ростовский государственный \\ университет путей сообщения»
}

Аннотация: в статье раскрывается тема влияния условий эксплуатации на изменение характеристик щебеночного основания.

Ключевые слова: грунт, щебень, метод вибрации, воздействие.

\section{INFLUENCE OF OPERATING CONDITIONS ON THE COEFFICIENT OF INTERNAL FRICTION IN THE CRUSHED STONE BASE}

\author{
Shapovalov Vladimir Vladimirovich \\ Kovalenko Oleg Igorevich \\ Cherniy Vladislav Igorevich \\ Nubaryan Daniel Vladimirovich
}

\begin{abstract}
: the article reveals the topic of the influence of operating conditions on the change in the characteristics of the crushed stone base.

Key words: soil, crushed stone, method vibration, impact.

В процессе работы различных строительных машин (копёров, турбогенераторов, молотов, виброкатков) из-за дисбаланса их движущихся элементов возникают временные действующие нагрузки, которые прикладываются к грунту в непродолжительные временные отрезки. Данные нагрузки способствуют появлению вибраций в грунте, которые в свою очередь значительно влияют на его свойства: уменьшают внутренние силы
\end{abstract}


сцепления и трения в грунтах, что приводит к появлению широкого ряда специфических событий. Минимизация сил трения при вибрировании в грунтах - важнейший фактор, влияющий на свойства грунтов.

Вибрация - это механические колебания тела. Один из простейших видов колебаний - общие. В этом случае тело периодически движется в устойчивом положении, как одно целое, то есть все его составляющие движутся с одной скоростью и в одном направлении. Как правило, вибрации тела появляются вследствие каких-либо сил возбуждения, которые являются приложенными к объекту с внешней или внутренней среды.

Вибрации определяются их амплитудой, частотой, силой возбуждения, направлением и углом воздействия на тело. Поэтому вибрационный анализ предоставляет возможность определить влияние, оказываемое машиной на грунт, балласт, песок и глину.

Для определения одной из главных характеристик - влияние частоты вибраций на угол естественного откоса была разработана модельная установка (Рис. 1). С помощью данной установки становится возможным опытным путем определить оптимальные частоты вибрации, воздействующей на балласт, сохраняя при этом минимальный уровень внутреннего трения в грунте.

Конструктивно установка (Рис. 2) состоит из: рамы 2, на которой закреплены амортизационные пружины 4 - виброизоляторами, не позволяющими гасить частоту вибрационного воздействия. Крупно фракционный щебень 5 высыпан в контейнер 3, который крепится на пружины 4 через жёсткое основание. Источником вибрации является дисбаланс 7, находящийся рядом с электродвигателем 1, который прикреплён к основанию контейнера. С помощью преобразователя напряжения 6 можно контролировать вибрационное воздействие благодаря регулированию частоты вращения вала электродвигателя. [1]

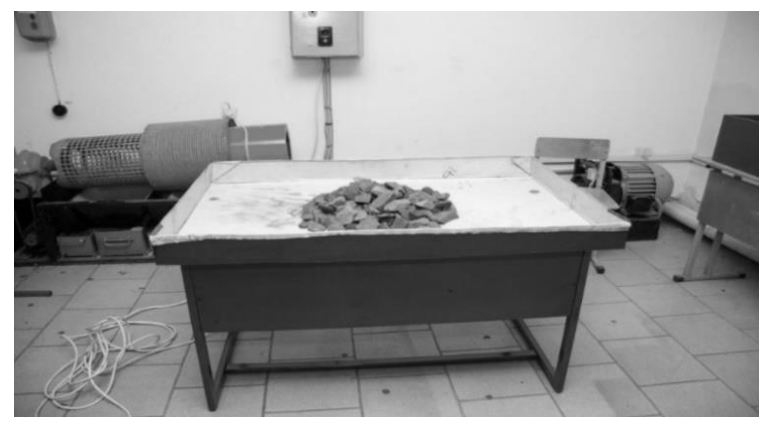

Рис. 1. Общий вид модельной установки 
Чтобы определить влияние условий эксплуатации на изменение характеристик щебеночного основания были проведены два эксперимента. В качестве экспериментального материала послужил щебень - продукт, который получают в результате добычи и дробления скальных горных пород. В результате первого было выявлено, что вибрационное воздействие на грунт зависит от состояния щебня. Опытным путем было определено оптимальное значение частоты вибрации для влажного балласта - 34 Гц, для сухого 32 Гц. (Рис. 3).
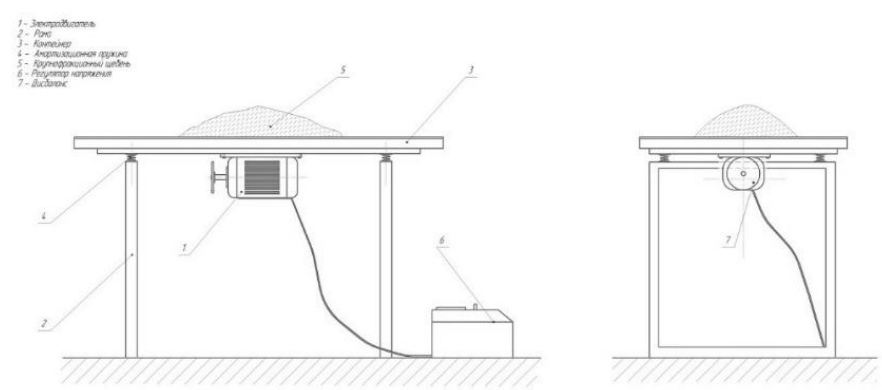

\section{Рис. 2. Схема экспериментальной установки}

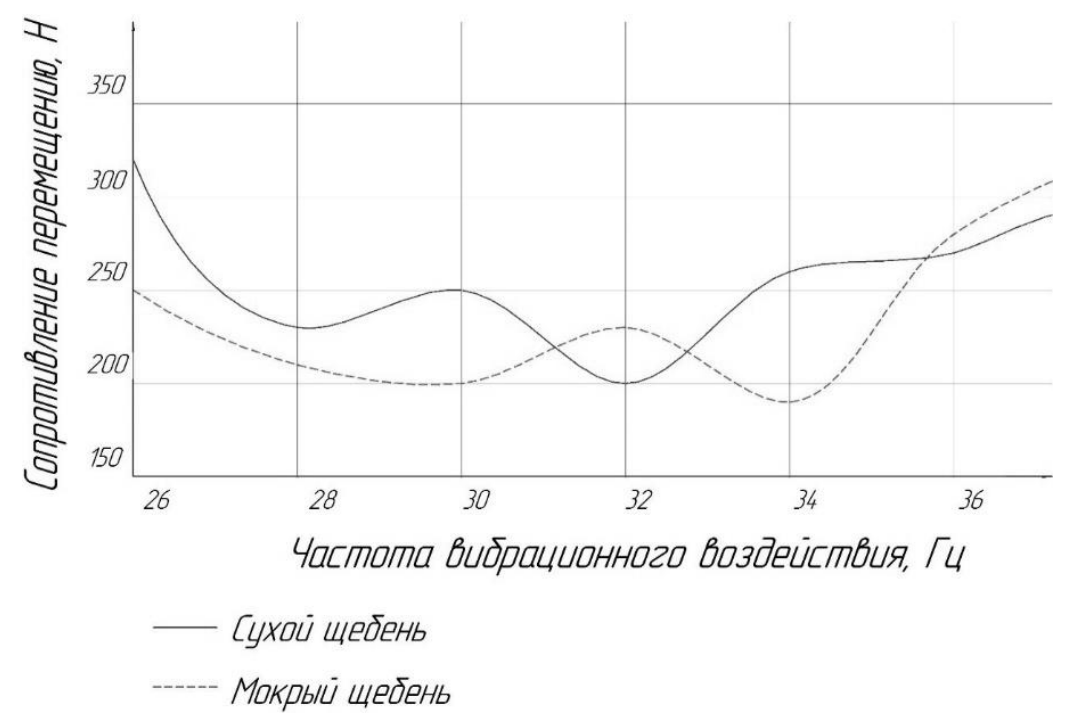

Рис. 3. Результаты первого эксперимента

В зависимости от загрязнённости щебня изменяется частота резонансного воздействия - чем грязнее щебень, тем она ниже. Поэтому в ходе второго эксперимента была расширена экспериментальная база добавлены чистый (Рис.4) и грязный (Рис.5) опытные образцы. Определены изменения угла естественного откоса, a, следовательно, и изменения 
коэффициента внутреннего трения в балласте, в зависимости от частоты вибрации.

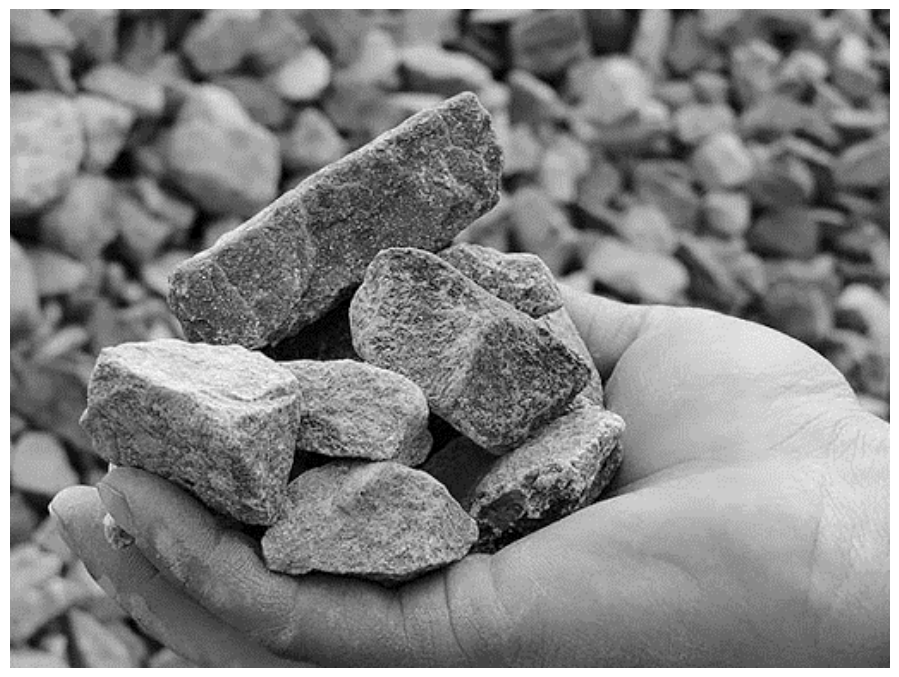

Рис. 4. Чистый экспериментальный щебень

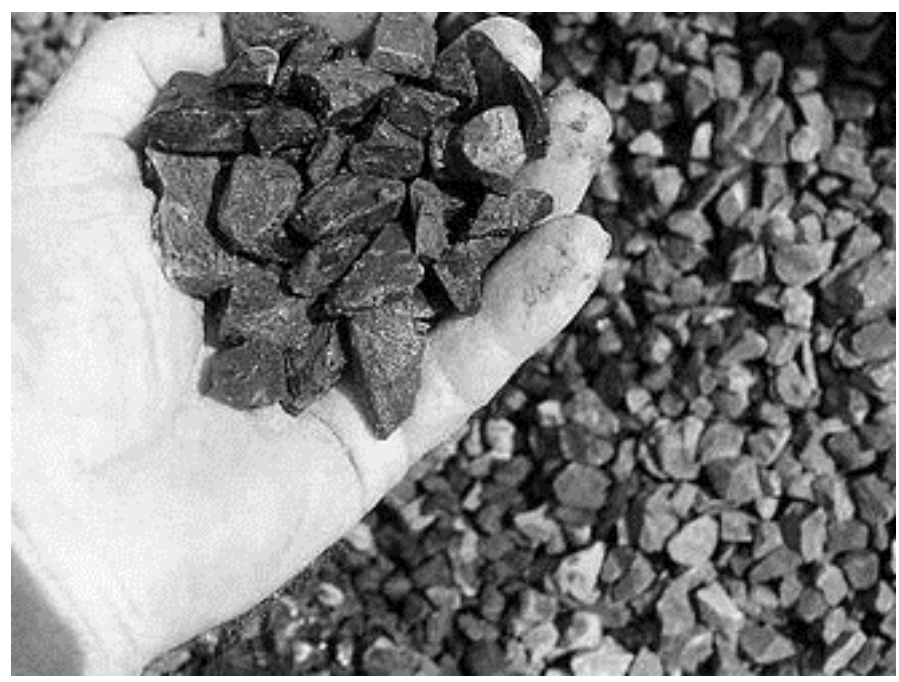

\section{Рис. 5. Грязный экспериментальный щебень}

По итогам опыта были выявлены следующие показатели (Рис. 6):

- Чистый сухой щебень - 34 Гц;

- Чистый мокрый щебень - 36 Гц;

- $\quad$ Грязный сухой щебень - 38 Гц;

- Грязный мокрый щебень - 36 Гц. 


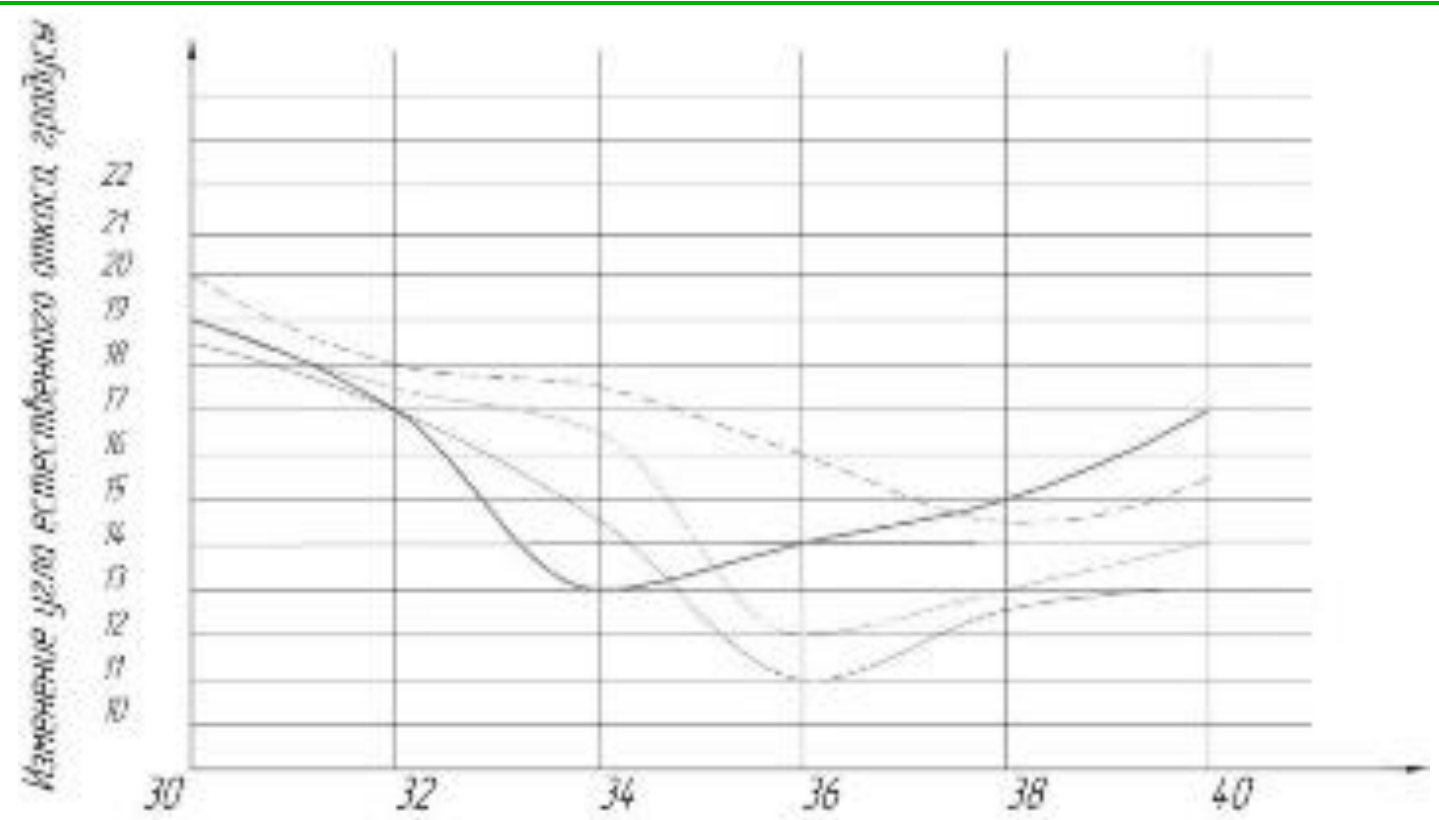

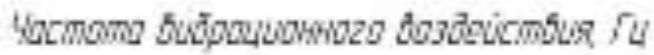

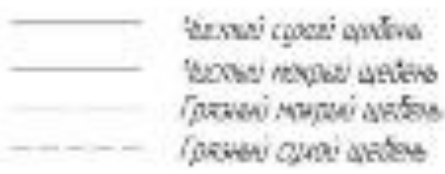

Рис. 6. Результаты второго эксперимента

Вибрационное воздействие так же применяют и для уплотнения грунта в ходе работ по улучшению свойств земляного полотна.

Способы уплотнения грунтов характеризуются принципом влияния специализированной техники на утрамбовываемый грунт. Выделяют три главных метода уплотнения: вибрированием, вибротрамбованием, и комбинированным воздействием. [2]

Уплотнение вибрированием строится на воздействии на грунт механических колебаний, передаваемых в ходе работы от основных органов машины (колес, плит, вибробулав). Данный метод разделяют на глубинный и поверхностный.

Поверхностное виброуплотнение грунта заключается в том, что орган уплотнения находится на поверхности грунта и, совершая колебательные движения, уплотняет его. Этот метод применяется для уплотнения малосвязных и несвязных грунтов обратных засыпок.

В отличие от поверхностного метода, при глубинном - рабочий орган находится не на поверхности уплотняемого грунта, а внутри него. Данный 
метод используется для уплотнения сыпучих грунтов, в том числе пребывающих в водонасыщенном состоянии.

Техника для уплотнения верхнего слоя грунта имеет возможность работы в виброударном режиме, исходя из главных параметров вибраций амплитуды и частоты колебаний. Работая в таком режиме, значительно возрастает амплитуда, но в то же время, частота колебаний уменьшается, в сравнение с вибрационными машинами. Таким образом, такая техника называется вибротрамбующей, а метод уплотнения, выполняемый ей вибротрамбованием.

Если на грунт влияют статические, вибрационные, вибротрамбующие и трамбующие нагрузки, применяют особый метод уплотнения комбинированный. Используют его, как правило, при широком фронте земельных работ со всеми видами грунта.

\section{Список литературы}

1. Шведов А.Ю., Повышение качества работ по виброуплотнению балласта: магистерская диссертация / А.Ю. Шведов, В.В. Шаповалов; ФГБОУ ВПО РГУПС. - Ростов н/д, 2016 - 95 с. - Библиогр.: с. 87-90.

2. Инструкция по устройству обратных засыпок грунта в стесненных местах. СН 536-81 / Госстрой СССР. - М; Стройиздат, 1982. -32 с. Библиогр: гл. 4.1., методы механического уплотнения грунтов.

(С) В.В. Шаповалов, О.И. Коваленко, В.И. Черный, Д.В. Нубарян, А.Ю. Шведов, 2020 